\section{Selective Molecular Recognition, C-H Bond Activation, and Catalysis in Nanoscale Reaction Vessels}

\author{
DOROTHEA FIEDLER, DENNIS H. LEUNG, \\ ROBERT G. BERGMAN, ${ }^{*, \dagger}$ AND \\ KENNETH N. RAYMOND*, \\ Chemical Sciences Division, Lawrence Berkeley National \\ Laboratory, and Department of Chemistry, University of \\ California, Berkeley, California 94720-1460 \\ Received July 14, 2004
}

\section{ABSTRACT}

Supramolecular chemistry represents a way to mimic enzyme reactivity by using specially designed container molecules. We have shown that a chiral self-assembled $\mathrm{M}_{4} \mathrm{~L}_{6}$ supramolecular tetrahedron can encapsulate a variety of cationic guests with varying degrees of stereoselectivity. Reactive iridium guests can be encapsulated, and the $\mathrm{C}-\mathrm{H}$ bond activation of aldehydes occurs with the host cavity controlling the ability of substrates to interact with the metal center based upon size and shape. In addition, the host container can act as a catalyst by itself. By restricting reaction space and preorganizing the substrates into reactive conformations, it accelerates the sigmatropic rearrangement of enammonium cations.

\section{Introduction}

Enzymes are among the most selective and active catalysts in nature. For example, the hydrolysis of the phosphate ester groups of DNA would take millions of years if uncatalyzed but occurs rapidly in vivo. In 1946, Linus Pauling introduced the idea that enzyme catalysis is due to transition state binding and suggested that "In order to catalyze a reaction an enzyme must recognize the transition state in a selective way, i.e., it must stabilize it better than the substrate."1 Jencks followed up on this idea in 1969 and proposed that an antibody raised against a

Dorothea Fiedler was born in Hamburg, Northern Germany, in 1978. She went to college at the University of Würzburg, Southern Germany, and received her Diplom in chemistry in 2001. Since then she has been pursuing her Ph.D. with R. G. Bergman and K. N. Raymond at U. C. Berkeley.

Dennis H. Leung was born in Fargo, North Dakota, in 1979. He obtained a B.A. degree from Cornell University in 2001, triple-majoring in chemistry, classics, and philosophy. He is currently a Ph.D. candidate, working under the guidance of R. G. Bergman and K. N. Raymond at U. C. Berkeley.

Robert G. Bergman was born in Chicago in 1942. He received his B.A. degree from Carleton College in 1963 and completed his Ph.D. under Jerome A. Berson's direction at the University of Wisconsin in 1966. After a one-year postdoctoral stay with Ronald Breslow at Columbia, he spent 11 years on the faculty at the California Institute of Technology before moving to his present joint position at U. C. Berkeley and Lawrence Berkeley National Laboratory in 1978.

Kenneth N. Raymond was born in Astoria, Oregon, in 1942. He received a B.A from Reed College 1964 and his Ph.D. from Northwestern University in 1968 under the direction of Fred Basolo and James Ibers. He joined the faculty of U. C. Berkeley in 1967. He is a Faculty Senior Scientist and Interim Director of the Seaborg Center, Lawrence Berkeley National Laboratory. transition state analogue could catalyze a particular reaction, ${ }^{2}$ and this suggestion was later realized in catalytic antibodies. ${ }^{3,4}$

What are the fundamental features of enzymatic catalysis that lead to such dramatic rate increases and high selectivities, and what does this imply for the use of synthetic supramolecular systems as catalysts? One component of the enzymatic efficiency is selective substrate recognition and binding. Once bound at the active site, the induced proximity of the two reactants, or two functional groups in the same reactant, dramatically increases the reaction rates. Changes in solvation may also provide significant rate increases, since the enzyme interior often is more hydrophobic than the surrounding aqueous solution. Specific functional groups in the active site may stabilize the reaction transition state. Understanding enzyme-catalyzed reactions requires separating these several factors that can simultaneously affect overall catalytic reactivity. ${ }^{5}$ In principle, this analysis is simpler in a synthetic host, which can be designed so that only confinement and desolvation of the guest substrate occur.

Host-guest chemistry, the use of supramolecular assemblies as hosts for chemical reactivity, is emerging as an important way to study how the binding of molecules into space-restricted environments can mediate their chemical reactivity. ${ }^{6-8}$ Much like enzymes, the size, shape, and chemical environment of an assembly cavity can help control the recognition and reactivity of substrate molecules, offering the potential for entirely new types of synthetic catalysts. Rather than using inner-sphere ligands to induce changes in reactivity, the outer-sphere environment of a self-assembled host cavity may be utilized to obtain selective reactivity. Reactions that usually require an organic solvent to accommodate an organometallic catalyst may be carried out in aqueous solution in the confined and protected hydrophobic cavity of a watersoluble supramolecular host.

This Account is intended to summarize current efforts toward achieving supramolecular reaction control and, ultimately, supramolecular catalysis with artificial selfassembled hosts. This task has been pursued with two different approaches: (1) the encapsulation of reactive transition metal complexes into a self-assembled host and (2) utilization of the container molecule as the catalyst itself.

\section{An $M_{4} L_{6}$ Tetrahedral Host Assembly}

The supramolecular coordination assemblies of $\mathrm{M}_{4} \mathrm{~L}_{6}$ stoichiometry that are used here have had their theoretical approach, realization, and characterization recently reviewed by Raymond and co-workers. ${ }^{9-11}$ This system consists of four metal atoms $\left(\mathrm{M}=\mathrm{Ga}^{3+}, \mathrm{Al}^{3+}, \mathrm{In}^{3+}\right.$, or $\left.\mathrm{Fe}^{3+}\right)$ situated at the corners of a tetrahedron and bridged by six naphthalene-based bis-bidentate catechol ligands

\footnotetext{
* To whom correspondence should be addressed.

† Fax: (+1) 510-642-7714. E-mail: bergman@cchem.berkeley.edu.

§ Fax: (+1) 510-486-5283. E-mail: raymond@socrates.berkeley.edu.
} 

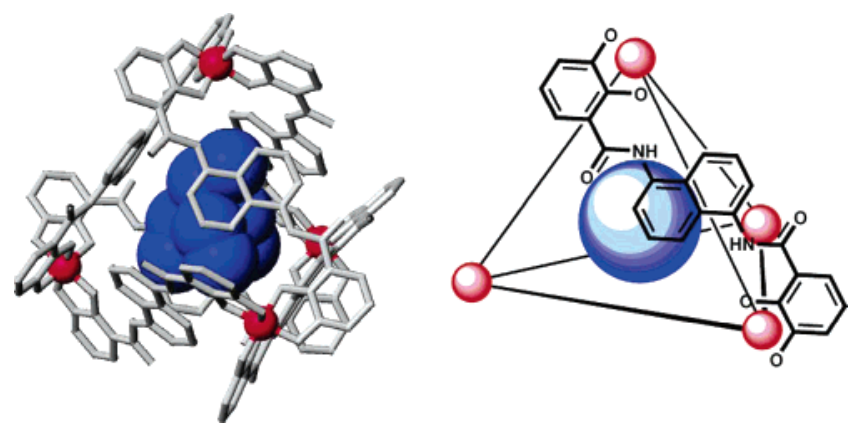

FIGURE 1. Model (left) of the crystal structure of $\left[\mathrm{NEt}_{4} \subset \mathrm{Fe}_{4} \mathrm{~L}_{6}\right]^{11-}$ and schematic (right) of $\left[\mathrm{G} \subset \mathrm{M}_{4} \mathrm{~L}_{6}\right]^{11-}$. Six bis-bidentate catechol amide ligands span the edges of the tetrahedron (only one of the ligands is drawn for clarity). Guest molecules are represented in blue and metals in red.

(Figure 1). The metal and ligand components are predisposed to self-assemble into exclusively this tetrahedral structure. The negatively charged container molecule (overall charge -12 ) is soluble in water and other polar solvents, but contains a hydrophobic cavity of between 0.35 and $0.5 \mathrm{~nm}^{3}$. It has been well established that these vessels encapsulate a variety of monocationic species, among them $\mathrm{NMe}_{4}{ }^{+}, \mathrm{NEt}_{4}{ }^{+}, \mathrm{PEt}_{4}{ }^{+}, \mathrm{Cp}_{2} \mathrm{Co}^{+}$, and $\mathrm{Cp}_{2} \mathrm{Fe}^{+}$ $\left(\mathrm{Cp}=\eta^{5}-\mathrm{C}_{5} \mathrm{H}_{5}\right)$, to form host-guest complexes of the general formula $\left[G \subset \mathrm{M}_{4} \mathrm{~L}_{6}\right]^{11-}(\subset$ denotes guest encapsulation within the host). ${ }^{12}$ The affinity of the guest molecules for the cavity depends on their size, hydrophobicity, enthalpy of desolvation, and charge. Though composed of achiral components, the overall structure of the tetrahedron is chiral. The chirality is a result of the trisbidentate coordination at each metal center, leading to either $\Delta$ or $\Lambda$ configuration. Due to strong mechanical coupling between the metal centers through the ligands, the chirality is communicated from one vertex to the next, exclusively resulting in homochiral tetrahedra (with either $\Delta, \Delta, \Delta, \Delta$ or $\Lambda, \Lambda, \Lambda, \Lambda$ configuration). Resolution of the racemic mixture is accomplished by addition of the enantioresolved (S)- $N$-methylnicotinium counterion followed by exchange of the resolving agent with achiral counterions $\mathrm{NMe}_{4}{ }^{+}$or $\mathrm{NEt}_{4}{ }^{+}$. This yields enantiopure and configurationally stable assemblies, providing a "chiral nanoscale flask". 13,14

\section{Encapsulation of Organometallic Complexes}

The pursuit of organometallic chemistry capable of proceeding within supramolecular assemblies requires the identification of guest molecules whose size, shape, and reactivity are compatible with the host system. Fujita and co-workers have conducted detailed studies on the hostguest chemistry of a Pd-based $\mathrm{M}_{6} \mathrm{~L}_{4}$ octahedral metalligand assembly. They discovered that four equivalents of ferrocene could be encapsulated into the highly charged host (overall charge +12 ). This complexation led to altered electrochemical behavior; the peak potential of bound ferrocene is positively shifted by $73 \mathrm{mV}$ compared with the unencapsulated molecule in aqueous solution. ${ }^{15}$
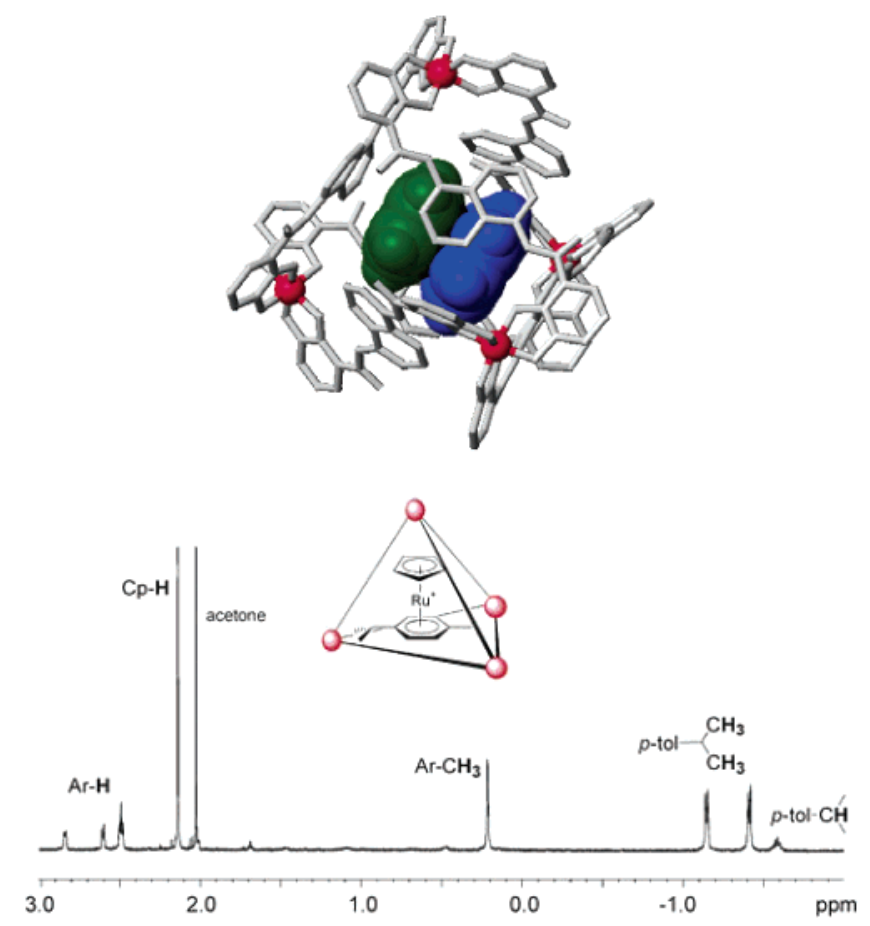

FIGURE 2. CAChe model (top) of $\left[\mathrm{CpRu}\left(\eta^{6}-\mathrm{C}_{6} \mathrm{H}_{6}\right) \subset \mathrm{Ga}_{4} \mathrm{~L}_{6}\right]^{11-}$ and ${ }^{1} \mathrm{H}$ NMR spectrum (bottom) of $\mathrm{K}_{11}\left[\mathbf{2} \subset \mathrm{Ga}_{4} \mathrm{~L}_{6}\right] . \eta^{5}-\mathrm{C}_{5} \mathrm{H}_{5}$ is represented in green, $\eta^{6}-\mathrm{C}_{6} \mathrm{H}_{6}$ in blue, and gallium in red.

In the tetrahedral nanovessel system studied by the Raymond group, the high affinity of the cationic sandwich complexes $\mathrm{Cp}_{2} \mathrm{Fe}^{+}$and $\mathrm{Cp}_{2} \mathrm{Co}^{+}$for the $\mathrm{M}_{4} \mathrm{~L}_{6}$ assembly stimulated our interest in the structurally similar ruthenium complexes $\left[\mathrm{CpRu}\left(\eta^{6}-\mathrm{C}_{6} \mathrm{H}_{6}\right)\right]^{+}(\mathbf{1})$ and $[\mathrm{CpRu}(p$ cymene) $]^{+}(2)$. Indeed, these complexes undergo guest exchange with the more weakly bound $\mathrm{NMe}_{4}{ }^{+}$, and the desired host-guest complexes are formed quantitatively. ${ }^{16}$ The generation of the host-guest complexes is most easily observed by ${ }^{1} \mathrm{H}$ NMR spectroscopy. The resonances of the encapsulated guest are shifted significantly upfield, due to shielding of the naphthalene moiety of the host assembly, illustrating the close contact between host and guest. For example, the guest resonances of $\mathrm{K}_{11}\left[\mathbf{1} \subset \mathrm{Ga}_{4} \mathrm{~L}_{6}\right]$ occur at $2.60 \mathrm{ppm}\left(\eta^{6}-\mathrm{C}_{6} \mathrm{H}_{6}\right)$ and $1.89 \mathrm{ppm}(\mathrm{Cp})$, whereas the signals for the unencapsulated ruthenium complex are at 6.04 and $5.29 \mathrm{ppm}$, respectively. Addition of more than 1 equiv of ruthenium complex did not increase the intensity of the signal for the encapsulated species. Instead, two new resonances are displayed at 4.93 and 4.58 ppm, indicating that additional $\mathbf{1}$ is ion-paired to the assembly exterior. This conclusion is supported by MM3optimized molecular modeling, which showed that the cavity is not large enough to accommodate more than 1 equiv of sandwich complex (Figure 2, top). ${ }^{17}$

The chiral environment of the cavity was probed by employing the complex $[\mathrm{CpRu}(p \text {-cymene })]^{+}(2)$ as a guest molecule. The isopropyl substituent bears two enantiotopic methyl groups. Upon binding by the chiral host, these two methyl groups become diastereotopic and therefore distinguishable by NMR spectroscopy; the organometallic species experiences the chirality of the cavity (Figure 2, bottom). 

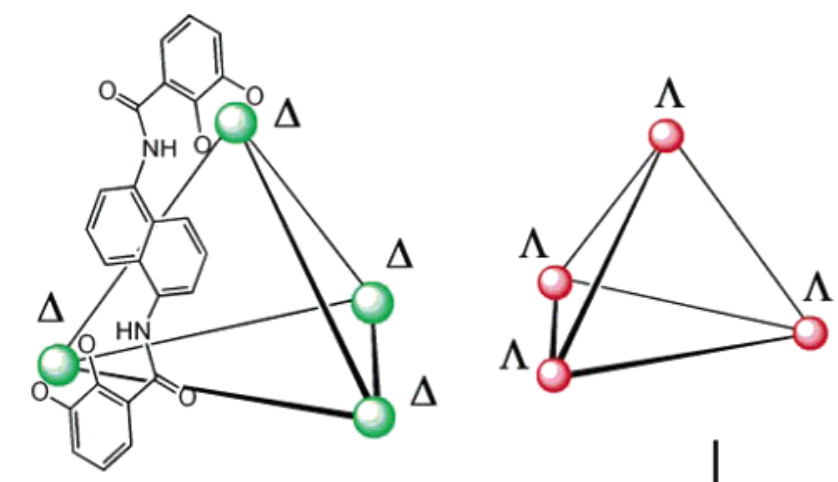

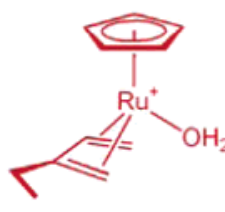

$S$

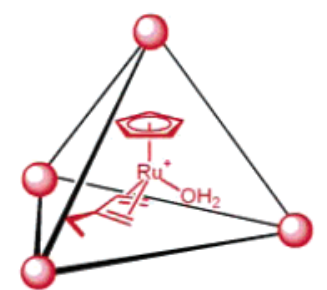

$\Lambda / S$

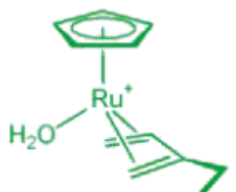

$R$

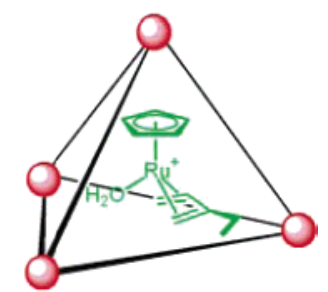

$\Lambda / R$ $\Delta / S$

$\Delta / R$

Enantiomers

Enantiomers

FIGURE 3. Combination of racemic $\mathrm{M}_{4} \mathrm{~L}_{6}$-assembly with chiral guests results in four different stereoisomers.

\section{Recognition of Chiral Guests}

In expanding the range of organometallic guests suitable for the $M_{4} L_{6}$ assemblies discussed here, we continued with the investigation of the similarly hydrophobic ruthenium half-sandwich complexes of the general formula $\mathrm{CpRu}$ (diene) $\mathrm{X}$ and $\mathrm{Cp}^{*} \mathrm{Ru}\left(\right.$ diene) $\mathrm{X}\left(\mathrm{Cp}^{*}=\eta^{5}-\mathrm{C}_{5}\left(\mathrm{CH}_{3}\right)_{5}\right)$, some of which are chiral. In polar media, these complexes undergo halide dissociation to form cationic solvated ruthenium species, which can be encapsulated into the tetrahedral assembly. ${ }^{18}$ The unsymmetrically substituted diene complexes are chiral and their encapsulation reveals an interesting stereochemical feature: the generation of two diastereomeric host-guest complexes. Combination of the racemic assembly with a racemic ruthenium complex results in four different host-guest stereoisomers $(\Delta / R, \Delta / S, \Lambda / R, \Lambda / S)$, that is, two diastereomeric pairs of enantiomers (Figure 3). This is reflected in the ${ }^{1} \mathrm{H}$ NMR spectra of the host-guest complexes: the spectra of $\mathrm{K}_{11}\left[\mathrm{CpRu}\right.$ (isoprene) $\left.\left(\mathrm{H}_{2} \mathrm{O}\right) \subset \mathrm{Ga}_{4} \mathrm{~L}_{6}\right]$ and $\mathrm{K}_{11}$ [CpRu(2-ethylbutadiene) $\left.\left(\mathrm{H}_{2} \mathrm{O}\right) \subset \mathrm{Ga}_{4} \mathrm{~L}_{6}\right]$ show two separate data sets for the two diastereomers in a 50:50 ratio.

To enhance stereoselective recognition, the sterically more demanding $\mathrm{Cp}^{*}$ ligand was employed, which should allow for closer host-guest contacts and higher levels of recognition. A series of 1 - and 2-substituted diene complexes were investigated, and the results are summarized in Table 1. This table establishes the key property that the degree of chiral recognition is highly size- and shapedependent. For example, the host-guest complex $\mathrm{K}_{11}$ [8 $\subset \mathrm{Ga}_{4} \mathrm{~L}_{6}$ ] shows very moderate diastereoselectivity (59:41).
Table 1. Observed Diastereomeric Ratios (dr's) in Host-Guest Complexes $\mathrm{K}_{11}\left[\mathrm{Cp} * \mathrm{Ru}(\operatorname{diene})\left(\mathrm{H}_{2} \mathrm{O}\right) \subset\right.$ $\mathrm{Ga}_{4} \mathbf{L}_{6}$ ]

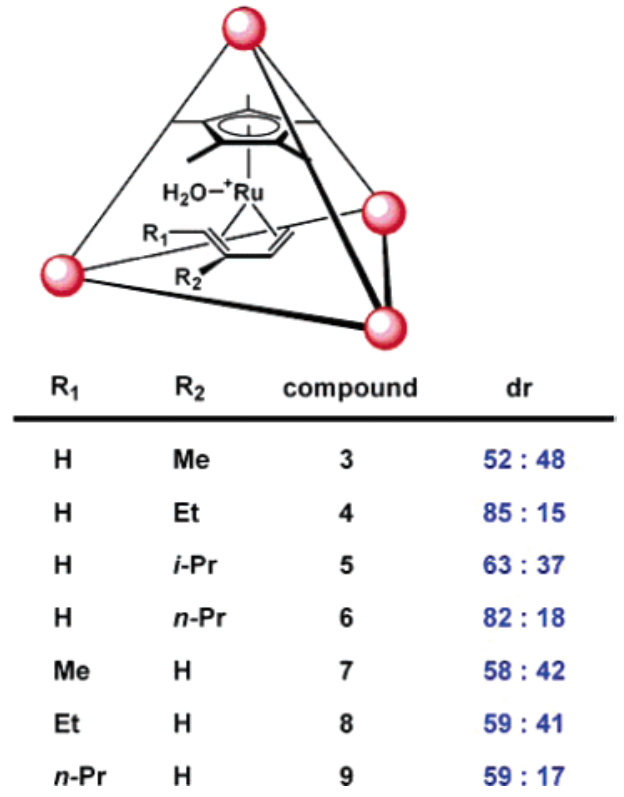

Moving the ethyl substituent to the 2-position has a dramatic effect: the ratio of diastereomers for $\mathrm{K}_{11}[4 \subset$ $\mathrm{Ga}_{4} \mathrm{~L}_{6}$ ] now amounts to 85:15 (Figure 4, bottom). Also important is the significant difference in recognition between $\left[\mathrm{Cp}^{*} \mathrm{Ru}\left(2 \text { - } i \text {-propylbutadiene) }\left(\mathrm{H}_{2} \mathrm{O}\right)\right]^{+}\right.$(5) and $\left[\mathrm{Cp}^{*} \mathrm{Ru}\left(2-n \text {-propylbutadiene) }\left(\mathrm{H}_{2} \mathrm{O}\right)\right]^{+}(\mathbf{6})\right.$ : the linear alkyl chain induces a higher degree of recognition compared 

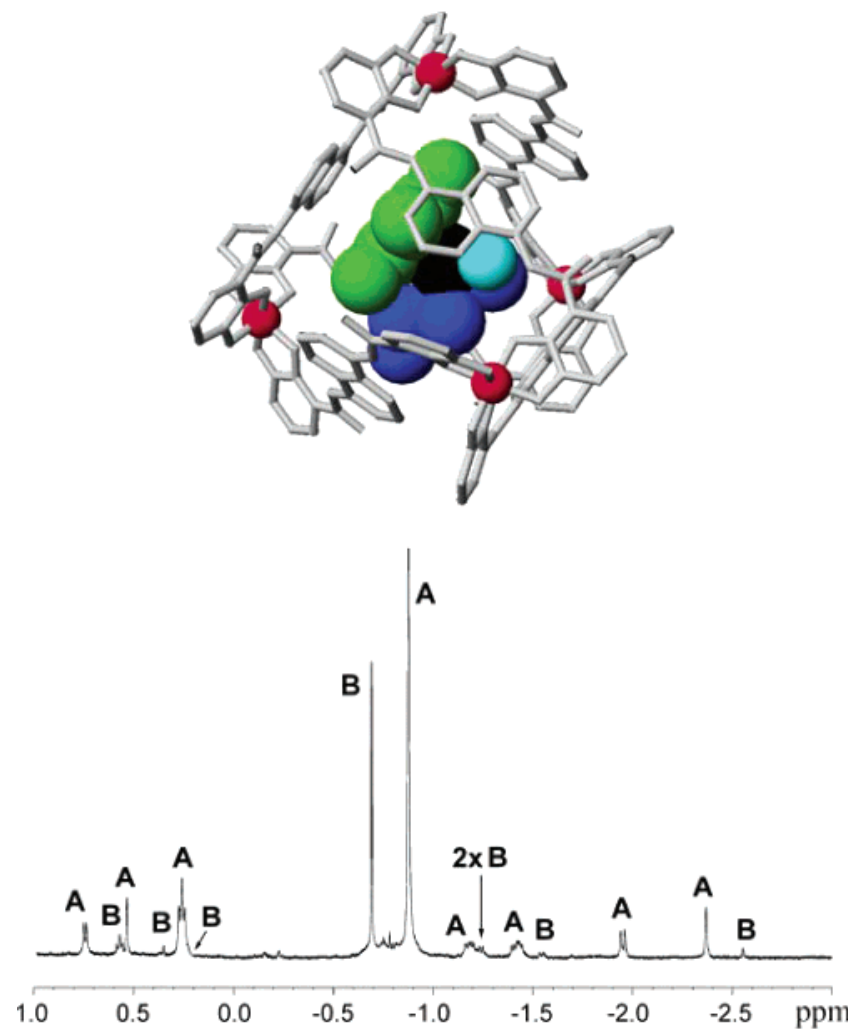

FIGURE 4. CAChe model (top) of [ $\mathrm{Cp}{ }^{*} \mathrm{Ru}$ (2-ethylbutadiene) $\left(\mathrm{H}_{2} \mathrm{O}\right) \subset$ $\left.\mathrm{Ga}_{4} \mathrm{~L}_{6}\right]^{11-}$ and ${ }^{1} \mathrm{H}$ NMR spectrum (bottom) of $\mathrm{K}_{11}\left[4 \subset \mathrm{Ga}_{4} \mathrm{~L}_{6}\right]$. Each signal of the major diastereomer $\mathrm{A}$ is accompanied by a smaller signal corresponding to the minor diastereomer B. $\eta^{5}-\mathrm{C}_{5}\left(\mathrm{CH}_{3}\right)_{5}$ is represented in green, 2-ethylbutadiene in blue, water in light blue, and gallium in red.

to the more spherical isopropyl substituent, again illustrating the high shape sensitivity.

At present, diastereomeric ratios of this magnitude are modest compared to those available using conventional reagents. However, considering that the recognition process relies only on weak van der Waals interactions, the observed selectivities are encouraging. The diastereomeric ratios compare favorably to those seen in other selfassembled host-guest systems in which recognition is governed by weak interactions such as van der Waals interactions or hydrogen bonding. For example, Rebek and co-workers have reported the self-assembly of a tetrameric chiral capsule with $D_{2}$ symmetry that is held together by a seam of hydrogen bonds. ${ }^{19}$ This capsule binds a variety of neutral organic molecules; particularly effective are guest molecules containing carbonyl groups. When racemic mixtures of chiral ketones are added to the chiral assembly, the ${ }^{1} \mathrm{H}$ NMR spectrum reveals the ratios of the diastereomeric host-guest complexes. Most remarkable is the complexation of 3-methylcyclohexanone, which is encapsulated with an 80:20 dr. ${ }^{19}$

Another example from the Rebek group describes enantioselective guest binding into a chiral dimeric "softball" constituted from achiral monomers. ${ }^{20}$ Here again diastereomeric ratios of up to 80:20 were observed for the encapsulation of chiral ketones. These guest binding studies with chiral substrates demonstrate that both steric and electrostatic effects are important in achieving chiral recognition; both the guest volume and shape, as well as the number of $\mathrm{CH} / \pi$ - and hydrogen-bond interactions, determine affinity and selectivity.

With the aforementioned observed diastereoselectivities, the enantiopure $\mathrm{M}_{4} \mathrm{~L}_{6}$ assembly was attractive as a potential resolving agent for the chiral organometallic species. Indeed, this has resulted in a dynamic resolution of enantiomers. ${ }^{18}$ Combination of 1 equiv of resolved $\Lambda$ assembly with only 1 equiv of $\mathrm{Cp} * \mathrm{Ru}$ (2-ethylbutadiene) $\mathrm{Cl}$ complex led to quantitative formation of $\mathrm{K}_{11}\left[4 \subset \mathrm{Ga}_{4} \mathrm{~L}_{6}\right]$. The isolated product gave rise to an intense CD signal, corroborating the formation of $\Lambda-\mathrm{K}_{11}\left[4 \subset \mathrm{Ga}_{4} \mathrm{~L}_{6}\right]$, a hostguest complex in which the host has fully retained its chirality. The ratio of diastereomers displayed in the ${ }^{1} \mathrm{H}$ NMR spectrum amounted to 85:15 again, which implies interconversion of the two $\left[\mathrm{Cp}^{*} \mathrm{Ru}(2\right.$-ethylbutadiene)$\left.\left(\mathrm{H}_{2} \mathrm{O}\right)\right]^{+}$enantiomers on the time scale of binding. We infer that water, as a labile ligand, facilitates rearrangement at the metal center. Similar behavior has been described for analogous cationic ruthenium complexes. ${ }^{21}$

\section{Encapsulated Transition Metal Reactivity}

Many organic transformations require the use of a transition metal catalyst but reports on the mediation of these metal-catalyzed transformations by supramolecular encapsulation are relatively rare, and catalytic accelerations are often modest. ${ }^{22-29}$ Since this Account is not intended to be a comprehensive review, but rather an illustration of a rapidly developing topic, only a few examples of such studies are discussed below.

Reek, van Leeuwen, and co-workers have used trispyridylphosphine ligands to coordinate to reactive metal centers such as rhodium and palladium. ${ }^{22-24}$ The pyridyl moieties on the phosphine ligand coordinate to zinc porphyrin complexes, which form well-defined molecular walls. Upon coordination of the phosphine to the metal center, molecular modeling indicates that the reactive metal center is completely encapsulated by the walls of the porphyrin assembly. The embedded metal complex gave rise to altered reactivity and selectivity. In particular, in rhodium-catalyzed hydroformylation reactions carried out at $25^{\circ} \mathrm{C}$, the porphyrin encapsulated complex showed up to 10 -fold higher activity and a $0.6: 1$ selectivity for the linear over the branched product. ${ }^{22,24}$

Hupp and co-workers have also utilized porphyrins as molecular panels around a reactive metal center ${ }^{25,26}$ When coordinative directed assembly is used with octahedral rhenium metal centers at the corners, in combination with zinc porphyrin walls, a supramolecular square with a large internal cavity is formed, where a catalytically active manganese porphyrin moiety binds to the zinc walls. Since the porphyrin walls prevent the bimolecular decomposition that is typical for the unbound catalyst, encapsulation results in improved catalyst stability and a 10- to 100-fold increase in the turnover numbers for epoxidation reactions of various alkenes..$^{25}$ In addition, catalyst encapsulation provides modest substrate size selectivity: larger 
Scheme 1. Proposed Mechanism of C-H Bond Activation of Aldehydes by the Iridium Ethylene Complex 12

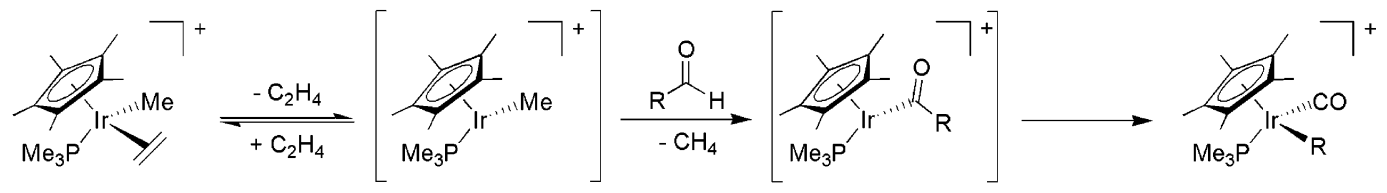

alkenes do not fit well within the cavity and react $3-4$ times slower than smaller alkenes.

There have been very few reports on the use of a chiral supramolecular environment to mediate transition metal reactivity. ${ }^{27-29}$ Lin and co-workers have employed metalligand interactions to self-assemble a chiral supramolecular triangle. ${ }^{27}$ The chirality of the structure is based on the use of enantiomerically pure 1,1'-bi-2-naphthol (BINOL) as building blocks. The dihydroxyl groups on the BINOL ligands point inward, creating a chiral pocket within the triangle. An increase to $90 \%$ enantioselectivity in diethylzinc additions to aldehydes was observed upon addition of a titanium catalyst to the triangle, compared to $80 \%$ enantioselectivity in the presence of only the free BINOLbased ligand. The sides of the triangle appear to be slightly flexible, allowing the pocket to accommodate aldehydes of various sizes.

The $\mathrm{M}_{4} \mathrm{~L}_{6}$ assembly studied by Raymond et al. enables the supramolecular encapsulation of cationic transition metal complexes without the need to covalently tie them to a surrounding superstructure. This provides for the potential encapsulation of discrete reactive species within the same host assembly by simple addition of the host and guest in aqueous solution. Furthermore, the $\mathrm{M}_{4} \mathrm{~L}_{6}$ host assembly has been shown to have significant enantioselective recognition of guests that could be harnessed for asymmetric reactivity with an achiral catalyst. ${ }^{18}$

Since half-sandwich ruthenium complexes proved to be adequate guests, we then investigated the encapsulation of other chemically reactive half-sandwich complexes. Bergman and co-workers have long been interested in the reactivity of half-sandwich iridium complexes..$^{30,31}$ In particular, the iridium(III) compound $\left[\mathrm{Cp}^{*}\left(\mathrm{PMe}_{3}\right) \operatorname{Ir}(\mathrm{Me}) \mathrm{OTf}\right]$ (10, OTf $=\mathrm{OSO}_{2} \mathrm{CF}_{3}=$ triflate) has been shown to thermally activate the $\mathrm{C}-\mathrm{H}$ bonds of organic molecules at room temperature..$^{32}$ Presumably this process occurs by dissociation of the labile triflate to form the cationic $16 \mathrm{e}^{-}$species $\left[\mathrm{Cp}^{*}\left(\mathrm{PMe}_{3}\right) \operatorname{Ir}(\mathrm{Me})\right]^{+}(\mathbf{1 1})$, which can then react with a $\mathrm{C}-\mathrm{H}$ bond.$^{33}$ Since the transition state of this reaction is monocationic, we hoped that encapsulation within the supramolecular host would allow for enforcement of guest selectivities.

The encapsulation of monocationic analogues of the iridium triflate species and its resulting reactivity were examined. ${ }^{34}$ By substituting a dative ligand for the covalently bound triflate at the metal center, stable cationic $18 \mathrm{e}^{-}$compounds of type $\left[\mathrm{Cp}^{*}\left(\mathrm{PMe}_{3}\right) \operatorname{Ir}(\mathrm{Me})(\mathrm{L})\right][\mathrm{OTf}](\mathrm{L}=$ donor ligand) can be prepared. If $\mathrm{L}$ is sufficiently labile, reactivity similar to that of the unencapsulated neutral triflate might be expected. The olefin adduct $\left[\mathrm{Cp}^{*}\left(\mathrm{PMe}_{3}\right)\right.$ $\left.\operatorname{Ir}(\mathrm{Me})\left(\mathrm{C}_{2} \mathrm{H}_{4}\right)\right][\mathrm{OTf}]$ (12) was prepared by addition of ethylene to a solution of $\mathbf{1 0}$ in $\mathrm{CH}_{2} \mathrm{Cl}_{2}$ and is stable in aqueous solution, since the ethylene ligand is more strongly coordinating than water to the iridium center. As a consequence of this stability, 12 has decreased reactivity compared to neutral triflate species. Upon addition of aldehyde substrates to $\mathbf{1 2}$ in aqueous solution, no reactivity was observed until the solution was heated to $75^{\circ} \mathrm{C}$. No reactivity with other organic substrates was observed before decomposition occurred at higher temperatures (aldehyde activation being much more facile than the activation of other organic substrates) ${ }^{32}$ In the proposed mechanism of this reaction, 12 first undergoes dissociation of ethylene at elevated temperatures. This generates the reactive $16 \mathrm{e}^{-}$intermediate 11 that can activate the aldehydic $\mathrm{C}-\mathrm{H}$ bond to release methane and form an iridium acyl complex. Decarbonylation of the acyl group gives an iridium alkyl carbonyl complex as the final reaction product (Scheme 1). ${ }^{30,35}$ Importantly, all of the intermediates in this reaction pathway are cationic and thus are likely to be mediated by encapsulation within the host cavity.

Combination of $\mathrm{Na}_{12}\left[\mathrm{Ga}_{4} \mathrm{~L}_{6}\right]$ with 12 in aqueous solution resulted in immediate and quantitative encapsulation to form $\mathrm{Na}_{11}\left[12 \subset \mathrm{Ga}_{4} \mathrm{~L}_{6}\right]$. As in the case of the encapsulated ruthenium compounds, the NMR resonances of the guest are shifted upfield. In addition, since the iridium center is chiral, encapsulation by the chiral host assembly results in the formation of two diastereomeric host-guest systems. In the ${ }^{1} \mathrm{H}$ NMR spectrum, the resonances corresponding to the $\mathrm{Cp}^{*}$ protons have been shifted upfield from a single signal at $1.96 \mathrm{ppm}$ for the unbound species to two diastereomeric peaks at -0.35 and $-0.44 \mathrm{ppm}$ (Figure 5). In the ${ }^{31} \mathrm{P}\left\{{ }^{1} \mathrm{H}\right\}$ NMR spectrum, the resonance corresponding to the trimethylphosphine peak has been shifted from a single peak at $-29.1 \mathrm{ppm}$ to two diastereomeric resonances at -37.1 and $-37.9 \mathrm{ppm}$. The diastereoselectivity of the encapsulation of $\mathbf{1 2}$ is relatively low $(\mathrm{dr}=53: 47)$. Molecular mechanics calculations on this system predicted an optimized structure in which $\mathbf{1 2}$ fits comfortably within the host cavity (Figure 5). ${ }^{17}$ The reactive metal center is completely enclosed within the walls of the host, providing a tight, well-defined nanospace around the iridium species.

Since the ethylene complex 12 displays $\mathrm{C}-\mathrm{H}$ bond activation reactivity at elevated temperatures, it was hoped that the corresponding host-guest assembly would display similar reactivity. When acetaldehyde was added to an aqueous solution of $\mathrm{Na}_{11}\left[\mathbf{1 2} \subset \mathrm{Ga}_{4} \mathrm{~L}_{6}\right]$ at $75^{\circ} \mathrm{C}$, a new encapsulated product was obtained in moderate yield after several days. This new product was identified as the host-guest assembly $\left[\mathrm{Cp}^{*}\left(\mathrm{PMe}_{3}\right) \operatorname{Ir}(\mathrm{Me})(\mathrm{CO}) \subset \mathrm{Ga}_{4} \mathrm{~L}_{6}\right]^{11-}$, 


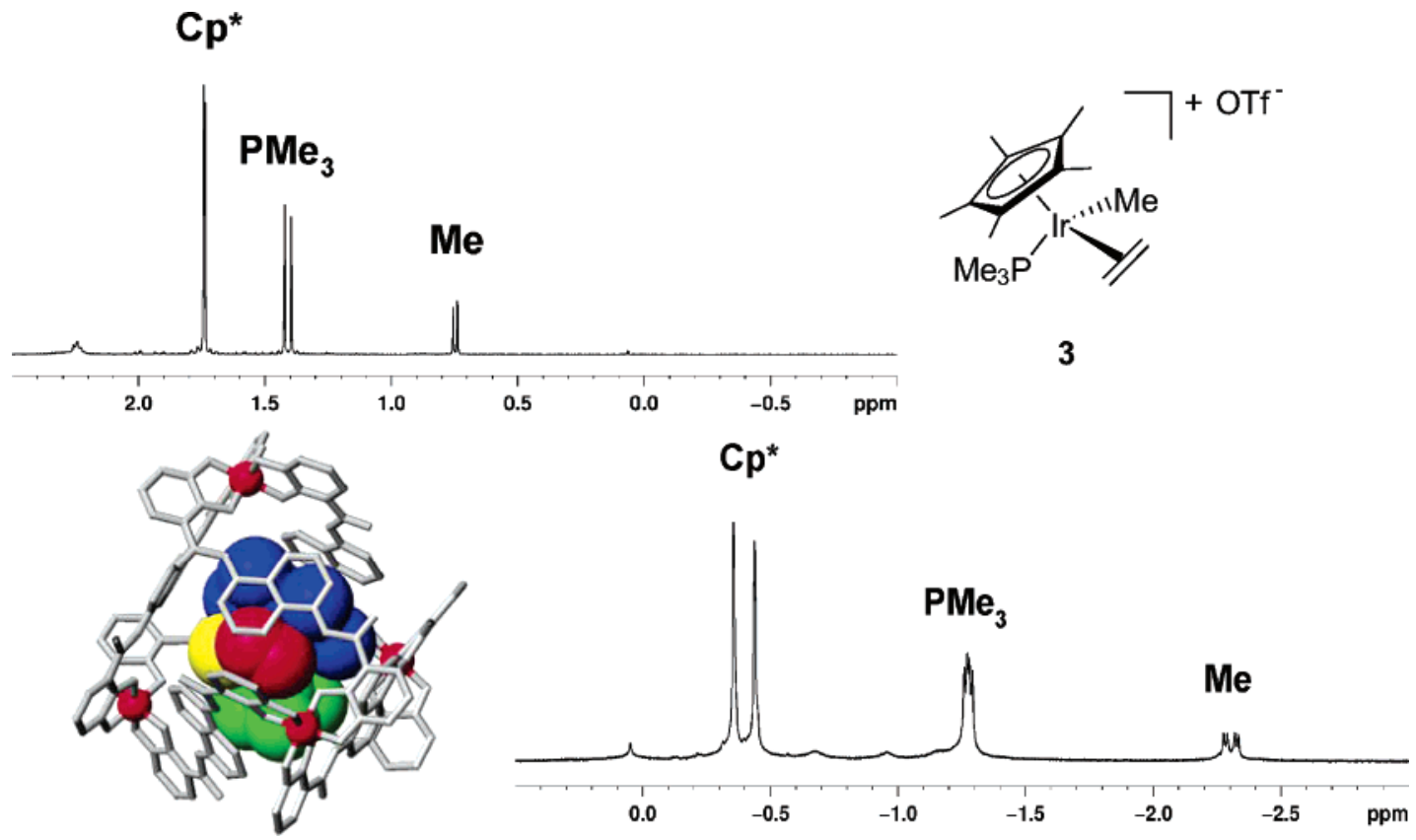

FIGURE 5. ${ }^{1} \mathrm{H}$ NMR spectrum (top) of unbound $12 \mathrm{D}_{2} \mathrm{O}$, CAChe model (bottom left) of $\mathrm{Na}_{11}\left[12 \subset \mathrm{Ga}_{4} \mathrm{~L}_{6}\right]$, and ${ }^{1} \mathrm{H}$ NMR spectrum (bottom right) of $\mathrm{Na}_{11}\left[12 \subset \mathrm{Ga}_{4} \mathrm{~L}_{6}\right]$ on the same axis. Two diastereomers are clearly distinguished.

the product of the $\mathrm{C}-\mathrm{H}$ bond activation of acetaldehyde. The product iridium carbonyl compound is also chiral, and was formed with a 60:40 diastereomeric ratio, although there is much lower diastereoselectivity in the original binding of 12 .

The selectivity of the activation of aldehydes by the encapsulated iridium species was explored by examining a wide variety of substrates. As expected, the host assembly strictly regulates the ability of aldehyde substrates to interact with the iridium center based on their size and shape. Large aldehydes such as benzaldehyde and pivalaldehyde do not react with the encapsulated iridium center. These substrates are too bulky to enter the host cavity. In contrast, smaller aldehydes are readily activated since they are able to approach the embedded reactive iridium center.

The selectivity cutoffs exhibited by this system are remarkable (Table 2). The host-guest assembly $\mathrm{Na}_{11}[\mathbf{1 2}$ $\subset \mathrm{Ga}_{4} \mathrm{~L}_{6}$ ] reacts with linear substrates ranging from acetaldehyde to $n$-butyraldehyde to form the corresponding encapsulated iridium carbonyl products. However, when the size of the aldehyde reaches valeraldehyde, no reaction is observed, since now the substrate is beyond the size regime allowed by the host cavity for reactivity. In addition to the size constraints enforced by encapsulation, significant shape selectivity was also observed. The encapsulated iridium complex reacts with isovaleraldehyde but not with 2-methylbutanal: simply moving the branching methyl group one position dramatically changes the ability of the substrate to react with the host-guest assembly.

As the size of the linear aldehyde substrates is increased homologously from acetaldehyde to propionaldehyde to butyraldehyde, the diastereoselectivity of the activation reaction increases from $60: 40$ to $65: 35$ to $70: 30$. Thus increasing the size of the organic substrate interacting with the iridium center produces a correspondingly stronger chiral recognition by the host cavity. In analogy to the results obtained with the ruthenium systems, branched substrates are activated with a lower degree of diastereoselectivity. The host-guest assembly reacts with isobutyraldehyde with a lower diastereoselectivity than butyraldehyde (dr of 55:45 vs 70:30).

This substrate selectivity can be observed in situ in a competition experiment with half of an equivalent of both acetaldehyde and benzaldehyde. When $\mathrm{Na}_{11}\left[\mathbf{1 2} \subset \mathrm{Ga}_{4} \mathrm{~L}_{6}\right]$ was added, upon heating, only the acetaldehyde substrate was activated, leaving benzaldehyde and half of an equivalent of unreacted $\mathrm{Na}_{11}\left[12 \subset \mathrm{Ga}_{4} \mathrm{~L}_{6}\right]$ in solution.

In considering the mechanism of the $\mathrm{C}-\mathrm{H}$ activation of aldehydes with the encapsulated iridium complex, it is important to examine the possibility that the reaction takes place by reversible dissociation of $\mathbf{1 2}$ into aqueous solution, followed by reaction with aldehyde and then reencapsulation of the product iridium carbonyl complex. The abrupt discontinuity in the dependence of reactivity on aldehyde size and shape discussed above provides evidence against this alternative mechanism. Experiments conducted in the absence of $\left[\mathrm{Ga}_{4} \mathrm{~L}_{6}\right]^{12-}$ host demonstrated that unencapsulated $\mathbf{1 2}$ reacts with all of the aldehydes shown in Table 2 at similar rates. Therefore, in the $\mathrm{C}-\mathrm{H}$ bond activation experiments carried out with the hostguest complex $\left[12 \subset \mathrm{Ga}_{4} \mathrm{~L}_{6}\right]^{11-}$, if the iridium guest were leaving the host interior, no unusual selectivity should be seen among aldehydes of various shapes and sizes. Because just the opposite is observed-that is, aldehydes that are too large or the wrong shape to enter and bind to the cationic metal center in the iridium-containing cavity are completely protected from undergoing decarbonylation-we conclude that the $\mathrm{C}-\mathrm{H}$ bond activation reaction takes place within the host assembly. 
Table 2. Observed Diastereoselectivities in the $\mathrm{C}-\mathrm{H}$ Bond Activation of Aldehydes by the $\mathrm{Na}_{11}\left[12 \subset \mathrm{Ga}_{4} \mathrm{~L}_{6}\right]$ Host-Guest Assembly
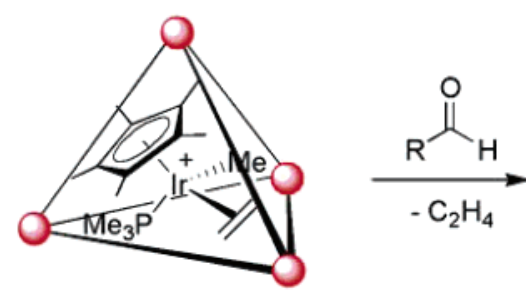

Substrate

dr<smiles>CC=O</smiles>

$45: 55$

$40: 60$

$30: 70$<smiles>CCCC=O</smiles><smiles>CCCCC=O</smiles>

n. r.<smiles>CC(C)(C)C=O</smiles>

$45: 55$<smiles>O=CC1CC1</smiles>

$42: 58$<smiles>O=CC1CCCC1</smiles>

n. r.<smiles>O=CC1CCCCC1</smiles>

n. $\mathbf{r}$.<smiles>O=Cc1ccccc1</smiles>

n. r.

$45: 55$

n. $\mathbf{r}$.

n. r.

\section{Catalysis by Self-Assembled Hosts}

Rather than encapsulating an organometallic catalyst into a container molecule for reaction with substrate, can the supramolecular host structure act alone as a catalyst? Such catalytic behavior can occur when two reactive partners are bound within the same capsule and their relative encounter frequencies ("effective concentrations") are increased dramatically. Rebek and co-workers have observed a 200-fold rate acceleration through encapsulation in the Diels-Alder reaction of benzoquinone and cyclohexadiene mediated by a hydrogen-bonded, selfassembled "softball”. Unfortunately, the reaction product is bound strongly by the capsule, preventing catalytic turnover. ${ }^{36,37}$ With a different dienophile, 2,5-dimethylthiophene dioxide, however, the product of the DielsAlder reaction was replaced from the softball by quinone and catalytic turnover was observed. With $10 \mathrm{~mol} \%$ of the "softball" the rate acceleration was 10 -fold. ${ }^{38}$

A different approach to supramolecular catalysis employs container molecules as phase-transfer catalysts operating in aqueous environments. This has been demonstrated by Fujita and co-workers, who utilized their Pdbased $\mathrm{M}_{6} \mathrm{~L}_{4}$ assembly as a catalyst for the Wacker oxidation of styrene to acetophenone. ${ }^{39}$ While their octahedral assembly bears an overall charge of +12 and is watersoluble, it encapsulates a variety of neutral, hydrophobic molecules. The Wacker oxidation of styrene, catalyzed by $\left[\mathrm{Pd}\left(\mathrm{NO}_{3}\right)_{2}(\mathrm{en})\right](\mathrm{en}=$ ethylene diamine $)$, affords very low
Scheme 2. General Schematic for the 3-Aza-Cope Rearrangement of Enammonium Cations (13) to Iminium Cations (14), Followed by Hydrolysis to Yield $\gamma_{,} \delta$-Unsaturated Aldehydes (15)<smiles>[R]C(=C)C([R16])[C@@H](C)C=O</smiles>

yield in water (4\%) due to the low solubility of the substrate. In the presence of a catalytic amount of the assembly, the yield of acetophenone is drastically increased to $82 \%$.

The demonstration of catalyis of a unimolecular reaction within the tetrahedral metal-ligand assembly is an attractive goal. To that end, the cationic 3-aza Cope reaction seemed ideal. The reaction occurs thermally in $N$-allyl enamine systems with varying degrees of facility depending on structural features, the cationic variant being more exothermic than the neutral version. The substrates are ammonium cations (13 in Scheme 2), very similar to $\mathrm{NMe}_{2} \mathrm{Pr}_{2}{ }^{+}$, which is known to be a strongly binding guest. ${ }^{12}$ The product of the rearrangement is an iminium cation (14), disposed to hydrolysis to the $\gamma, \delta$-unsaturated aldehyde (15). Since neutral molecules are bound weakly, or not at all, by the host-assembly, the aldehyde should be displaced rapidly by more enammonium substrate, 


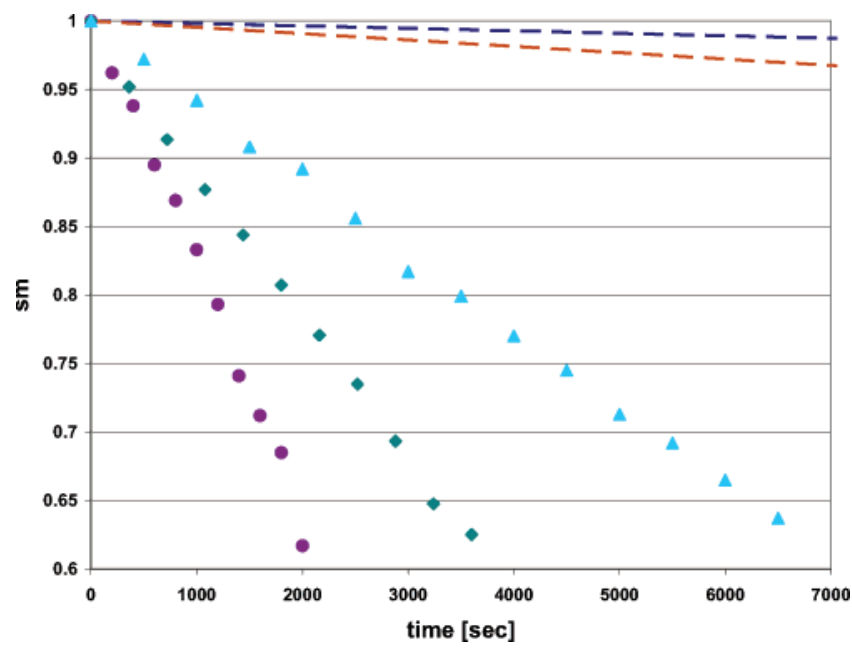

FIGURE 6. Initial rates (plotted as disappearance of starting material (SM) in mole fraction) at $25{ }^{\circ} \mathrm{C}$ for the catalytic 3-Aza Cope rearrangement of 13c: (O) $40 \%$ catalyst loading; $(-27 \%$ catalyst loading; ( $\mathbf{\Delta})$ 13\% catalyst loading; (red, - - -) 40\% catalyst loading inhibited with 8 equiv $\mathrm{NEt}_{4}^{+}$; (black, - - -) uncatalyzed reaction.

potentially allowing for turnover. Last, if the substrate is substituted unsymmetrically $\left(R_{2} \neq R_{3}\right)$, the rearrangement leads to the generation of a stereogenic center, raising the opportunity for asymmetric catalysis.

The dimethylallyl-(2-methylpropenyl)ammonium cation (13a, $R_{1}, R_{2}, R_{3}=H$ ) was encapsulated into the $M_{4} L_{6}$ assembly in aqueous solution to yield quantitatively $\mathrm{K}_{5}\left(\mathrm{NMe}_{4}\right)_{6}\left[\mathbf{1 3 a} \subset \mathrm{Ga}_{4} \mathrm{~L}_{6}\right] .{ }^{40}$ The rearrangement of both the free and encapsulated enammonium cation was monitored by ${ }^{1} \mathrm{H}$ NMR spectroscopy in $\mathrm{D}_{2} \mathrm{O}$ at $50{ }^{\circ} \mathrm{C}$ in buffered solution $(\mathrm{pD}=8.02)$. The rearrangement displayed clean first-order kinetics for the disappearance of starting material. The rates of rearrangement for the free and encap-
Table 3. Rate Constants for Free and Encapsulated Reactions and Their Acceleration Factors

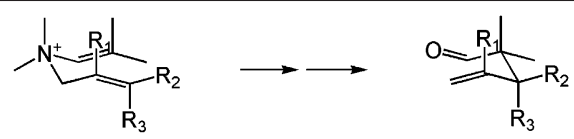

\begin{tabular}{|c|c|c|c|c|c|c|}
\hline substrate & $\mathbf{R}_{\mathbf{1}}$ & $\mathbf{R}_{\mathbf{2}}$ & $\mathbf{R}_{\mathbf{3}}$ & $\begin{array}{c}\mathbf{k}_{\text {free }} \\
{\left[\times 10^{-5} \mathrm{~s}^{-1}\right]}\end{array}$ & $\begin{array}{c}\mathbf{k}_{\text {encaps. }} \\
{\left[{\left.\mathrm{x} 10^{-5} \mathrm{~s}^{-1}\right]}^{-1}\right.}\end{array}$ & acceleration \\
\hline $\mathbf{1 3 a}$ & $\mathrm{H}$ & $\mathrm{H}$ & $\mathrm{H}$ & 3.49 & 16.3 & 5 \\
\hline $\mathbf{1 3 b}$ & $\mathrm{Me}$ & $\mathrm{H}$ & $\mathrm{H}$ & 7.61 & 198 & 26 \\
\hline $\mathbf{1 3 c}$ & $\mathrm{H}$ & $\mathrm{Et}$ & $\mathrm{H}$ & 3.17 & 446 & 141 \\
\hline $\mathbf{1 3 d}$ & $\mathrm{H}$ & $\mathrm{H}$ & $\mathrm{Et}$ & 1.50 & 135 & 90 \\
\hline $\mathbf{1 3 e}$ & $\mathrm{H}$ & $n-\mathrm{Pr}$ & $\mathrm{H}$ & 4.04 & 604 & 150 \\
\hline $\mathbf{1 3 f}$ & $\mathrm{H}$ & $\mathrm{H}$ & $n-\mathrm{Pr}$ & 1.69 & 74.2 & 44 \\
\hline $\mathbf{1 3 g}$ & $\mathrm{H}$ & $i-\mathrm{Pr}$ & $\mathrm{H}$ & 0.37 & 316 & 854 \\
\hline
\end{tabular}

sulated reaction differ significantly: the encapsulated reaction is accelerated by about a factor of $5\left(k_{\text {free }}=3.49\right.$ $\times 10^{-5} ; k_{\text {encaps }}=16.3 \times 10^{-5} \mathrm{~s}^{-1}$ ). The initial suspicion that this acceleration could be due to solvent effects (the cavity interior providing a more hydrophobic environment) or charge effects (the high negative charge of the assembly stabilizing the cationic transition state) was not supported by additional kinetic measurements of the unencapsulated rearrangement. No substantial solvent dependence was detected $\left(k_{\mathrm{D}_{2} \mathrm{O}}=3.49 \times 10^{-5} ; k_{\mathrm{MeOD}}=3.62 \times 10^{-5} ; k_{\mathrm{CDCl}_{3}}=\right.$ $\left.3.84 \times 10^{-5} \mathrm{~s}^{-1}\right)$, nor did added salt cause a substantial acceleration $\left(k_{\mathrm{D}_{2} \mathrm{O} / \mathrm{KCl}}=4.02 \times 10^{-5} \mathrm{~s}^{-1}\right)$.

To explore the causes of the rate increase within the capsule, additional substrates were investigated. Their rate constants for rearrangement (free and encapsulated) are summarized in Table 3. It is evident from these values

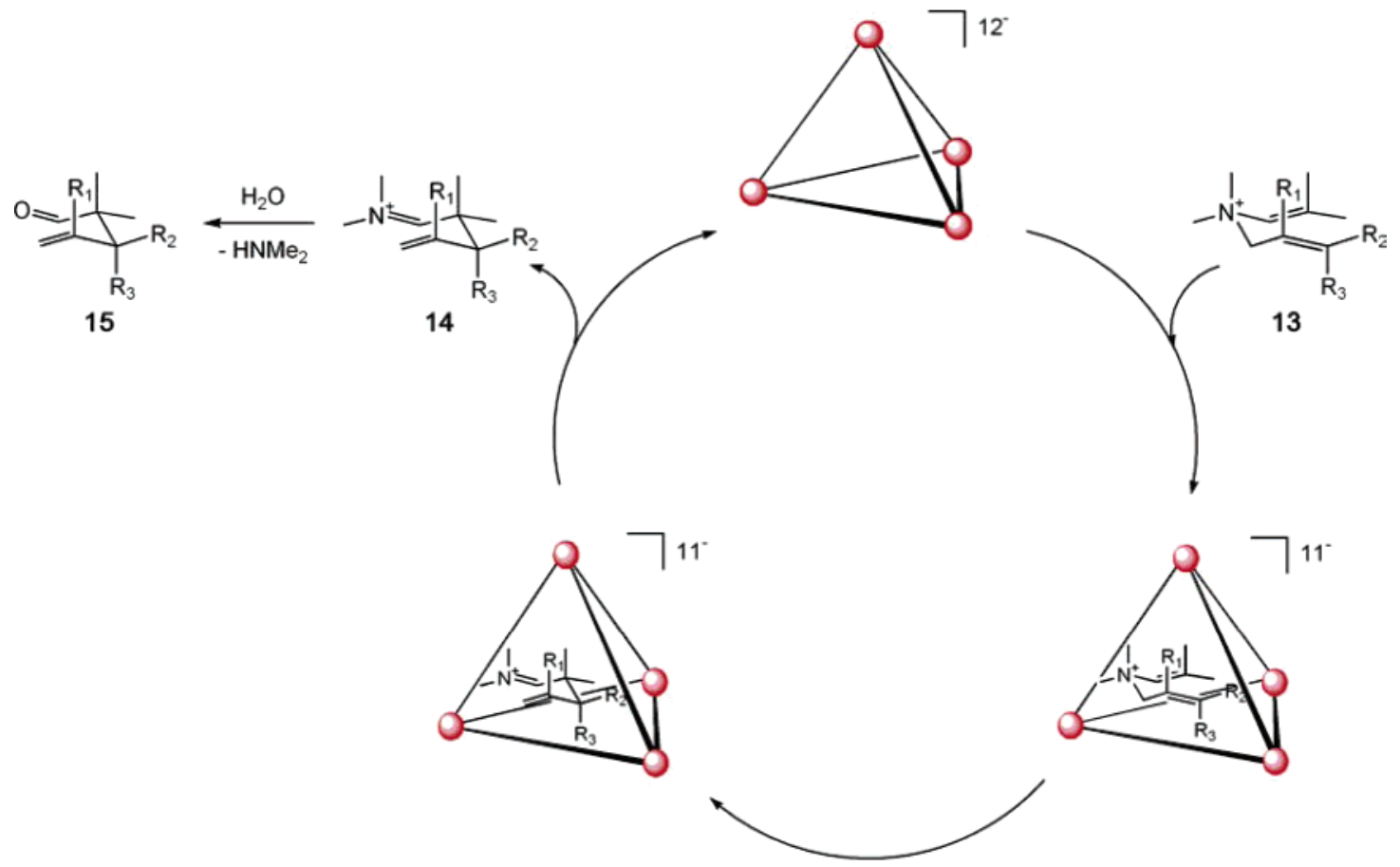

FIGURE 7. Proposed catalytic cycle of 3-aza Cope rearrangement catalyzed by the metal-ligand assembly. 
that additional substituents on the enammonium cation enhance the rearrangement rate of encapsulated substrates. Substrate 13e, for example, experienced 150-fold rate acceleration once encapsulated by the supramolecular host. Even more notable is the effect on the isopropylsubstituted enammonium cation 13g; an acceleration factor of 854 is observed. In pursuit of elucidating the origin of acceleration, the activation parameters for the rearrangement of free and encapsulated enammonium cation $13 c\left(R_{1}, R_{3}=H, R_{2}=E t\right)$ were determined. For the free rearrangement, $\Delta H^{\ddagger}=23.1 \pm 0.8 \mathrm{kcal} / \mathrm{mol}$ and $\Delta S^{\ddagger}$ $=-8 \pm 2 \mathrm{eu}$. The encapsulated reaction shows an almost identical enthalpy of activation, $\Delta H^{\ddagger}=23.0 \pm 0.9 \mathrm{kcal} /$ mol, but the entropy of activation differs remarkably, amounting to $\Delta S^{\ddagger}=2 \pm 3 \mathrm{eu}$. Therefore, a major contribution to the observed rate accelerations is the reduction of the entropy of activation. Upon encapsulation, the substrate loses several rotational degrees of freedom and appears to be preorganized into a reactive conformation. The tighter the host-guest fit, the greater the effect of preorganization becomes.

Aware that the product of rearrangement is released from the cavity and hydrolyzes in aqueous solution, we explored the possibility of carrying out the reaction under catalytic conditions. Kinetic experiments with different catalyst loadings confirmed truly catalytic behavior of the self-assembled host for the 3-aza Cope rearrangement of 13c (Figure 6). Raising the catalyst loading from 13 to 27 to $40 \mathrm{~mol} \%$, resulted in the expected rate accelerations; the observed rate constants at $25{ }^{\circ} \mathrm{C}$ are $k_{13 \%}=0.64 \times$ $10^{-4}, k_{27 \%}=1.17 \times 10^{-4}$, and $k_{40 \%}=1.80 \times 10^{-4} \mathrm{~s}^{-1}$.

Significantly, the addition of $\mathrm{NEt}_{4}{ }^{+}$, a very strongly binding guest that blocks the cavity interior, inhibited the reaction. With this information, we propose the catalytic cycle depicted in Figure 7. First, the metal-ligand assembly binds the enammonium substrate into its cavity. This encapsulation orients the substrate in a reactive conformation, prone to rearrangement. The rearranged product is ejected from the cavity and hydrolyzes, allowing the next catalytic cycle to begin.

\section{Future Perspective}

The utilization of self-assembled supramolecular architectures as nanoscale reaction vessels is still in its infancy. Even though a broad range of such structures have been reported, their properties as catalytic reaction chambers have rarely been exploited. The results in this field represent a way to harness the method employed by enzymes in nature for use in synthetic applications to attain new selectivities beyond current techniques. The findings reported here display the features desired from a chiral nanoflask. Operating in aqueous solution, these metal-ligand assemblies not only are able to selectively bind their substrates but have also proven their ability to control organometallic reactivity and mediate organic reactions catalytically. Future challenges include exploring the enantioselective induction of the resolved chiral host to achieve asymmetric catalysis and to increase the scope of reactivity within these supramolecular structures.
This work was supported by the Director, Office of Energy Research, Office of Basic Energy Sciences, Chemical Sciences Division, of the U.S. Department of Energy under Contract No. DE-AC03-7600098.

\section{References}

(1) Pauling, L. Molecular Architecture and Biological Reactions. Chem. Eng. News 1946, 24, 1375-1377.

(2) Jencks, W. P. Catalysis in Chemistry and Enzymology; McGrawHill: New York, 1969.

(3) Tramontano, A.; Janda, K. D.; Lerner, R. A. Catalytic Antibodies. Science 1986, 234, 1566-1570.

(4) Pollack, S. J.; Jacobs, J. J.; Schultz, P. G. Selective Chemical Catalysis by an Antibody. Science 1986, 234, 1570-1573.

(5) Borman, S. Much Ado About Enzyme Mechanisms. Chem. Eng. News 2004, 82, 35-39.

(6) Cram, D. J. Cavitands: Organic Hosts with Enforced Cavities. Science 1983, 219, 1177-1183.

(7) Cram, D. J. Molecular Container Compounds. Nature 1992, 356, $29-36$.

(8) Lehn, J.-M. Supramolecular Chemistry: Concepts and Perspectives; VCH: Weinheim, Germany, 1995.

(9) Caulder, D. L.; Brückner, C.; Powers, R. E.; König, S.; Parac, T. N.; Leary, J. A.; Raymond, K. N. Design, Formation and Properties of Tetrahedral $\mathrm{M}_{4} \mathrm{~L}_{4}$ and $\mathrm{M}_{4} \mathrm{~L}_{6}$ Supramolecular Clusters. J. Am. Chem. Soc. 2001, 123, 8923-8938.

(10) Caulder, D. L.; Raymond, K. N. Supermolecules by Design. Acc. Chem. Res. 1999, 32, 975-982.

(11) Yeh, R. M.: Davis, A. V.: Raymond, K. N. In Comprehensive Coordination Chemistry Il; Meyer, T. J., Ed.; Elsevier Ltd.: Oxford, U.K., 2004; pp 327-355

(12) Parac, T. N.; Caulder, D. L.; Raymond, K. N. Selective Encapsulation of Aqueous Cationic Guests into a Supramolecular Tetrahedral $\mathrm{M}_{4} \mathrm{~L}_{6}(12-)$ Anionic Host. J. Am. Chem. Soc. 1998, 120 8003-8004.

(13) Terpin, A. J.; Ziegler, M.; Johnson, D. W.; Raymond, K. N. Resolution and Kinetic Stability of a Chiral Supramolecular Assembly Made of Labile Components. Angew. Chem., Int. Ed. 2001, 40, 157-160.

(14) Ziegler, M.; Davis, A. V.; Johnson, D. W.; Raymond, K. N. Supramolecular Chirality: A Reporter of Structural Memory. Angew. Chem., Int. Ed. 2003, 42, 665-668.

(15) Sun, W. Y.; Kusukawa, T.; Fujita, M. Electrochemically Driven Clathration/Declathration of Ferrocene and its Derivatives by a Nanometer-Sized Coordination Cage. J. Am. Chem. Soc. 2002, 124, 11570-11571.

(16) Fiedler, D.; Pagliero, D.; Brumaghim, J. L.; Bergman, R. G.; Raymond, K. N. Encapsulation of Cationic Ruthenium Complexes into a Chiral Self-Assembled Cage. Inorg. Chem. 2004, 43, 846848.

(17) CAChe, 5.04 ed.; Fujitsu Limited, 2002.

(18) Fiedler, D.; Leung, D. H.; Bergman, R. G.; Raymond, K. N. Enantioselective Guest Binding and Dynamic Resolution of Cationic Ruthenium Complexes by a Chiral Metal-Ligand Assembly. J. Am. Chem. Soc. 2004, 126, 3674-3675.

(19) Nuckolls, C.; Hof, F.; Martin, T.; Rebek, J., Jr. Chiral Microenvironments in Self- Assembled Capsules. J. Am. Chem. Soc. 1999, 121, 10281-10285.

(20) Rivera, J. M.; Martin, T.; Rebek, J., Jr. Chiral Softballs: Synthesis and Molecular Recognition Properties. J. Am. Chem. Soc. 2001, $123,5213-5220$.

(21) Matsushima, Y.; Onitsuka, K.; Takahashi, S. Enantioface-Selective Coordination of Prochiral 1,3-Dienes to Planar-Chiral Cyclopentadienyl-Ruthenium Complexes. Organometallics 2004, 23, 2439-2446.

(22) Slagt, V. F.; Reek, J. N. H.; Kramer, P. C. J.; van Leeuwen, P. W. N. M. Assembly of Encapsulated Transition Metal Catalysts. Angew. Chem., Int. Ed. 2001, 40, 4271-4274.

(23) Slagt, V. F.; van Leeuwen, P. W. N. M.; Reek, J. N. H. Multicomponent Porphyrin Assemblies as Functional Bidentate Phosphte Ligands for Regioselective Rhodium-Catalyzed Hydroformylation. Angew. Chem., Int. Ed. 2003, 42, 5619-5623.

(24) Slagt, V. F.; Kramer, P. C. J.; van Leeuwen, P. W. N. M.; Reek, J. N. H. Encapsulation of Transition Metal Catalysts by LigandTemplate Directed Assembly. J. Am. Chem. Soc. 2004, 126, 15261536.

(25) Merlau, M. L.; Mejia, M. d. P.; Nguyen, S. T.; Hupp, J. T. Artifical Enzymes Formed through Directed Assembly of Molecular Square Encapsulated Epoxidation Catalysts. Angew. Chem., Int. Ed. 2001, $40,4239-4242$. 
(26) Morris, G. A.; Nguyen, S. T.; Hupp, J. T. Enhanced Activity of Enantioselective (Salen)Mn(III) Epoxidation Catalysts Through Supramolecular Complexation. J. Mol. Catal. A: Chem. 2001, 174, $15-20$.

(27) Lee, S. J.; Hu, A.; Lin, W. The First Chiral Organometallic Triangle for Asymmetric Catalysis. J. Am. Chem. Soc. 2002, 124, 1294812949.

(28) Jiang, H.; Hu, A.; Lin, W. A Chiral Metallacyclophane for Asymmetric Catalysis. Chem. Commun. 2003, 96-97.

(29) Gianneschi, N. C.; Bertin, P. A.; Nguyen, S. T.; Mirkin, C. A.; Zakharov, L. N.; Rheingold, A. L. A Supramolecular Approach to an Allosteric Catalyst. J. Am. Chem. Soc. 2003, 125, 10508-10509.

(30) Arndtsen, B. A.; Bergman, R. G.; Mobley, T. A.; Peterson, T. H. Selective Intermolecular Carbon-Hydrogen Bond Activation by Synthetic Metal Complexes in Homogeneous Solution. Acc. Chem. Res. 1995, 28, 154-162.

(31) Klei, S. R.; Golden, J. T.; Burger, P.; Bergman, R. G. Cationic Ir(III) Alkyl and Hydride Complexes: Stoichiometric and Catalytic $\mathrm{C}-\mathrm{H}$ Activation by $\mathrm{Cp}^{*}\left(\mathrm{PMe}_{3}\right) \operatorname{Ir}(\mathrm{R})(\mathrm{X})$ in Homogeneous Solution. J. Mol. Catal. A: Chem. 2002, 189, 79-94.

(32) Burger, P.: Bergman, R. G. Facile Intermolecular Activation of C-H Bonds in Methane and Other Hydrocarbons and $\mathrm{Si}-\mathrm{H}$ Bonds in Silanes with the $\operatorname{Ir}(\mathrm{III})$ Complex $\mathrm{Cp} *\left(\mathrm{PMe}_{3}\right) \operatorname{Ir}\left(\mathrm{CH}_{3}\right)(\mathrm{OTf})$. J. Am. Chem. Soc. 1993, 115, 10462-10463.

(33) Tellers, D. M.; Yung, C. M.; Arndtsen, B. A.; Adamson, D. R.; Bergman, R. G. Electronic and Medium Effects on the Rate of Arene $\mathrm{C}-\mathrm{H}$ Bond Activation by Cationic Ir(III) Complexes. J. Am. Chem. Soc. 2002, 124, 1400-1410.
(34) Leung, D. H.; Fiedler, D.; Bergman, R. G.; Raymond, K. N. Selective $\mathrm{C}-\mathrm{H}$ Bond Activation by a Supramolecular Host-Guest Assembly. Angew. Chem., Int. Ed. 2004, 43, 963-966.

(35) Alaimo, P. J.; Arndtsen, B. A.; Bergman, R. G. Alkylation of Iridium via Tandem Carbon-Hydrogen Bond Activation/Decarbonylation of Aldehydes. Access to Complexes with Tertiary and Highly Hindered Metal-Carbon Bonds. Organometallics 2000, 19, 21302143.

(36) Kang, J. M.; Rebek, J., Jr. Acceleration of a Diels-Alder Reaction by a Self- Assembled Molecular Capsule. Nature 1997, 385, 5052.

(37) Kang, J. M.; Hilmersson, G.; Santamaria, J.; Rebek, J., Jr. DielsAlder Reactions Through Reversible Encapsulation. J. Am. Chem. Soc. 1998, 120, 3650-3656.

(38) Kang, J. M.; Santamaria, J.; Hilmersson, G.; Rebek, J., Jr. SelfAssembled Molecular Capsule Catalyzes a Diels-Alder Reaction. J. Am. Chem. Soc. 1998, 120, 7389-7390.

(39) Ito, H.; Kusukawa, T.; Fujita, M. Wacker Oxidation in an Aqueous Phase Through the Reverse Phase-Transfer Catalysis of a SelfAssembled Nanocage. Chem. Lett. 2000, 598-599.

(40) Fiedler, D.; Bergman, R. G.; Raymond, K. N. Supramolecular Catalysis of a Unimolecular Transformation: Aza-Cope Rearrangement within a Self-Assembled Host. Angew. Chem., Int. $E d$., in press.

AR040152P 